Article

\title{
Output Current Ripple Reduction Algorithms for Home Energy Storage Systems
}

\author{
Jin-Hyuk Park, Hae-Gwang Jeong and Kyo-Beum Lee * \\ Department of Electrical and Computer Engineering, Ajou University, San 5, Woncheon-dong, \\ Yeongtong-gu, Suwon 443-749, Korea; E-Mails: powerword87@gmail.com (J.H.P.); \\ lite88@ajou.ac.kr (H.G.J.)
}

* Author to whom correspondence should be addressed; E-Mail: kyl@ajou.ac.kr; Tel.: +82-31-219-2376; Fax: +82-31-212-9531.

Received: 26 August 2013; in revised form: 14 October 2013 / Accepted: 17 October 2013 / Published: 22 October 2013

\begin{abstract}
This paper proposes an output current ripple reduction algorithm using a proportional-integral (PI) controller for an energy storage system (ESS). In single-phase systems, the DC/AC inverter has a second-order harmonic at twice the grid frequency of a DC-link voltage caused by pulsation of the DC-link voltage. The output current of a $\mathrm{DC} / \mathrm{DC}$ converter has a ripple component because of the ripple of the DC-link voltage. The second-order harmonic adversely affects the battery lifetime. The proposed algorithm has an advantage of reducing the second-order harmonic of the output current in the variable frequency system. The proposed algorithm is verified from the PSIM simulation and experiment with the $3 \mathrm{~kW}$ ESS model.
\end{abstract}

Keywords: second-order harmonic; energy storage system; harmonic compensator; single phase grid connected inverter

\section{Introduction}

Recently, there has been growing interest in energy storage systems (ESSs) because of their use as a renewable energy supply and power increases at peak hours [1]. The ESS allows the highly efficient usage and stable management of power. When the power demand is low, the ESS stores electricity. On the other hand, the ESS provides this stored electricity when the power demand is high [2-4]. 
The grid-side power pulsates at twice the grid frequency because the voltage and the current on the grid are AC components. This causes a $120 \mathrm{~Hz}$ ripple on the battery-side voltage and current $[5,6]$. In single-phase systems, a second-order harmonic component occurs systematically. In ESS, the lifetime of the battery is an important issue for the power efficiency. The reactive power is generated by an internal impedance of the battery and current ripple. This reactive power causes an increase in the temperature of the battery, which reduces the battery lifetime. The lifetime of the battery is affected by temperature, current ripple, overcharge and so on [7]. In order to reduce the harmonics component in the grid connected system, passive power filters (PPFs), active power filters (APFs), digital algorithms and proportional-resonant (PR) controller are proposed. PPFs have the advantage that the filter can be easily designed by using passive devices like inductors and capacitors, but PPFs have problems such as detuning, resonance, instability and limitation of the possible frequency adjustment [8,9]. APFs can reduce the harmonic component using the compensation current which has the opposite phase of the harmonic component. However, APFs have a high operation cost, due to their extra hardware and complex control [10]. Unlike PPFs and APFs, digital algorithms which use a calculated ripple current compensation method do not cause an increase of the cost and volume. The calculated ripple current compensation method can reduce the harmonic current without complex calculations. However, this method cannot completely reduce harmonic current when the parameters are changing under various conditions [11]. Because of these problems, the ripple rejection algorithm with a proportional-resonant (PR) controller is proposed in [12,13]. A proportional-resonant (PR) controller has a high gain and a narrow bandwidth at the resonant frequency. If the resonant frequency of the PR controller is designed to the second-order harmonic frequency, the harmonic compensator using the PR controller extracts and controls the second-order harmonic component. However, the harmonic compensator using the PR controller sufficiently does not reduce the second-order harmonic component during frequency variation [14-16].

This paper proposes a second-order harmonic reduction algorithm using the PI controller. The conventional method for reducing the second-order harmonic does not sufficiently reduce the second-order harmonic component during the frequency variation. The proposed algorithm has an advantage of reducing the second-order harmonic during frequency variation situations. The current ripple reduction improves the lifetime of the battery. The proposed algorithm is verified by PSIM simulation and experiments for a $3 \mathrm{~kW}$ home ESS.

\section{Energy Storage System Topology}

Figure 1 shows a general grid-connected ESS in single-phase system. The ESS consists of a battery, bi-directional DC/DC converter, bi-directional DC/AC inverter and filter. An interleaved topology composed of two converters connected in parallel is used to reduce the switching ripple in the battery-side current. Because the ESS needs the bi-directional power transfer, a bi-directional DC/DC converter and the bi-directional DC/AC inverter are required. The DC/AC inverter controls the DC-link voltage and power factor. On the other hand, the DC/DC converter regulates the output current. 
Figure 1. Block diagram of the ESS.

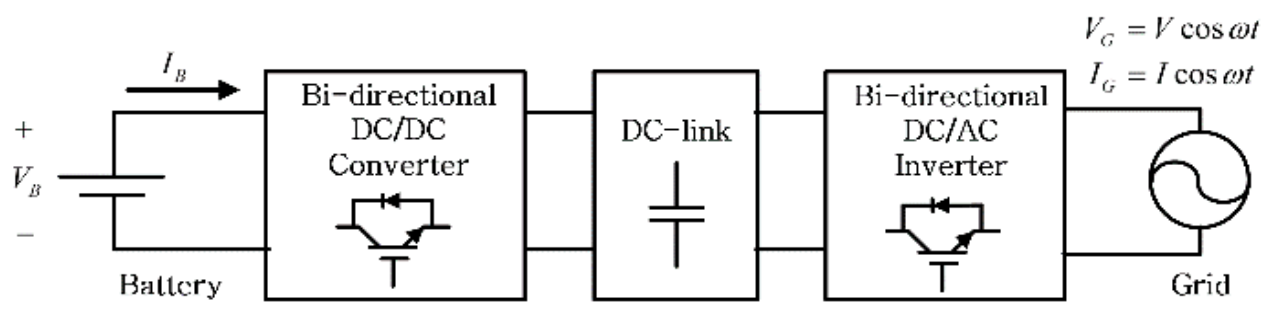

\subsection{Grid Connected DC/AC Inverter}

The full-bridge topology is adopted to set the DC/AC inverter for the proposed ESS as shown in Figure 2. The single-phase full-bridge inverter converts from the AC to DC constant voltage. Figure 3 shows a block diagram of the control scheme for the grid connected inverter in the single-phase system. This inverter regulates the DC-link voltage using a typical PI controller. To use the PI controller, a synchronous reference frame is required. In the single system, there is a need to create an imaginary axis because only one axis exists. An all pass filter (APF) has characteristic which passes all frequencies equally and shifts the phase by 90 degrees. The APF is used to make an imaginary axis because of the characteristics mentioned above. The phase angle which is estimated by the phase locked loop (PLL) is used in the synchronous reference frame. The grid voltage and current are converted to active and reactive components by using the synchronous reference frame and APF. The output of the DC-link controller is the active component which is the reference grid current. The inverter controls the power factor at 1 because the current controller controls the reactive component at zero and the active component to the reference grid current.

Figure 2. Construction of the grid connected inverter.

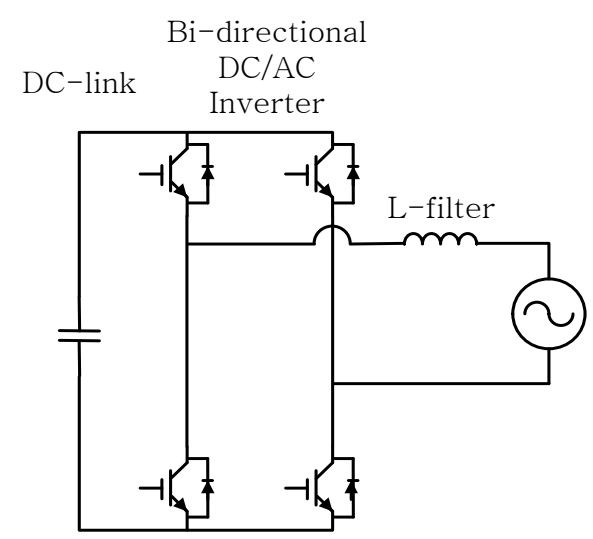

The DC-link controller is the main-controller and the current controller is the sub-controller as shown in Figure 3. In the charging mode, when the reference DC-link voltage is higher than the DC-link voltage, the DC-link voltage controller increases the reference grid current. The DC-link voltage controller decreases the reference grid current in the reverse case. 
Figure 3. Block diagram of the control scheme for the grid connected inverter.

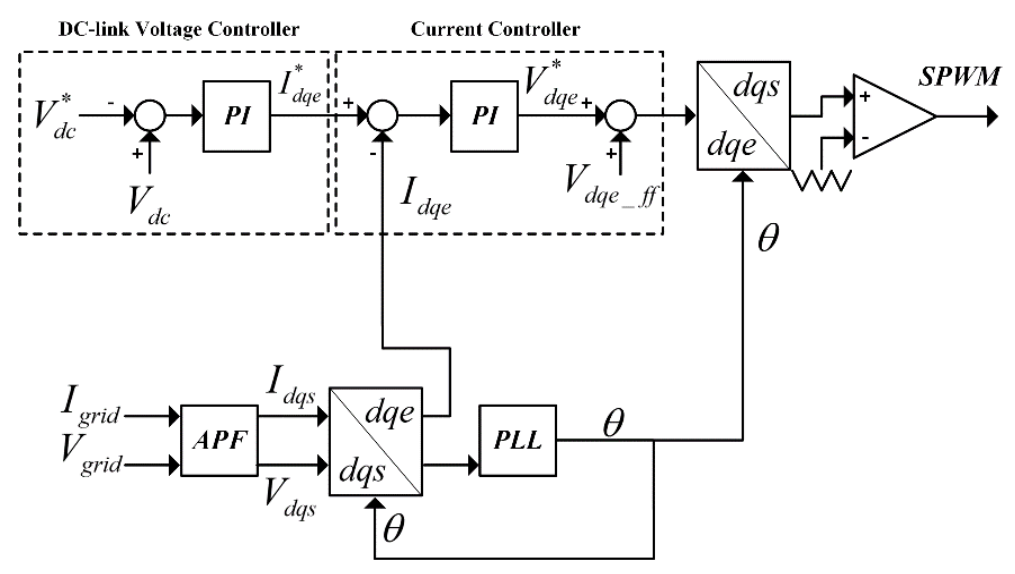

\subsection{DC/DC Converter}

Figure 4 shows the interleaved bi-directional converter used in the proposed ESS. The bi-directional converter is composed of a power semi-conductor switch, capacitor, and inductor. The bi-directional converter can operate in buck and boost mode according to the power flow of the ESS. The converter works with the buck mode in the charging mode and with the boost mode in the discharging mode.

Figure 4. Construction of the bi-directional DC/DC converter.

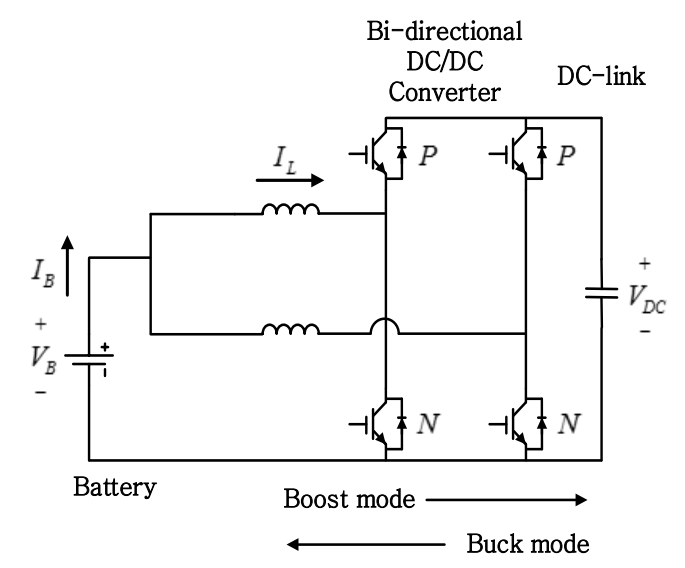

To reduce the current ripple of the converter, an interleaved topology is used. The interleaved converter has many advantages over a single phase converter. In the interleaved topology, the total current ripple is reduced due to the current of each phase being overlapped and there is an effect where the switching frequency is two times higher than that of the single phase topology. Also, the stress of the switch is smaller because the total current is divided into two phases.

Figure 4 shows the bi-directional DC/DC converter. When the system operates in the charging mode, the converter operates in buck mode. The buck mode converter produces a lower average output voltage than the input voltage. The output average voltage is linearly varied by the duty ratio $D_{\text {buck }}$ which is the ratio of the on time of the switch $\mathrm{P}$ and the period of switching [17]. The switch $\mathrm{N}$ works as a freewheeling diode and is complementarily switching P. Under this condition, the DC-link provides energy to the battery as well as to the inductor because the current flows from the DC-link to the battery. In a steady state, the voltage transfer ratio $G_{v}$ is: 


$$
G_{v}=\frac{V_{o}}{V_{\text {in }}}=\frac{V_{B}}{V_{D C}}=D_{b u c k}
$$

Because $D_{\text {buck }}$ is between 0 and $1, V_{B}$ is always lower than that of the DC-link.

When the system operates the discharging mode, the converter operates in boost mode. Unlike the buck mode, the output voltage is always greater than the input voltage in the boost mode. By varying the duty ratio $D_{\text {boost }}$ which is the ratio of the on time of the switch $\mathrm{N}$, the output average voltage is controlled. P is complementarily switching N. In boost mode, the input voltage is the voltage of battery and the output voltage is the voltage of the DC-link.

The battery provides energy to the DC-link because the current flows from the battery to the DC-link. In a steady state, the voltage transfer ratio $G_{v}$ is:

$$
G_{v}=\frac{V_{o}}{V_{\text {in }}}=\frac{V_{D C}}{V_{B}}=\frac{1}{1-D_{\text {boost }}}
$$

Because $D_{\text {boost }}$ is between 0 and $1, V_{D C}$ is always higher than $V_{B}$.

\subsection{Mechanism of $120 \mathrm{~Hz}$ Ripple Occurrence}

Figure 5 shows the ESS grid connected system in the single-phase system. The power equations for the grid-side and DC-link-side are:

$$
\begin{gathered}
P_{D C}=V_{D C} I_{D C} \\
P_{G}=V \cos \omega t \times I \cos \omega t=\frac{V I(1+\cos 2 \omega t)}{2}=\frac{V I}{2}+\frac{V I \cos 2 \omega t}{2}
\end{gathered}
$$

where $\omega(=2 \pi f)$ is the frequency of the grid.

Figure 5. Construction of the grid connected ESS system.

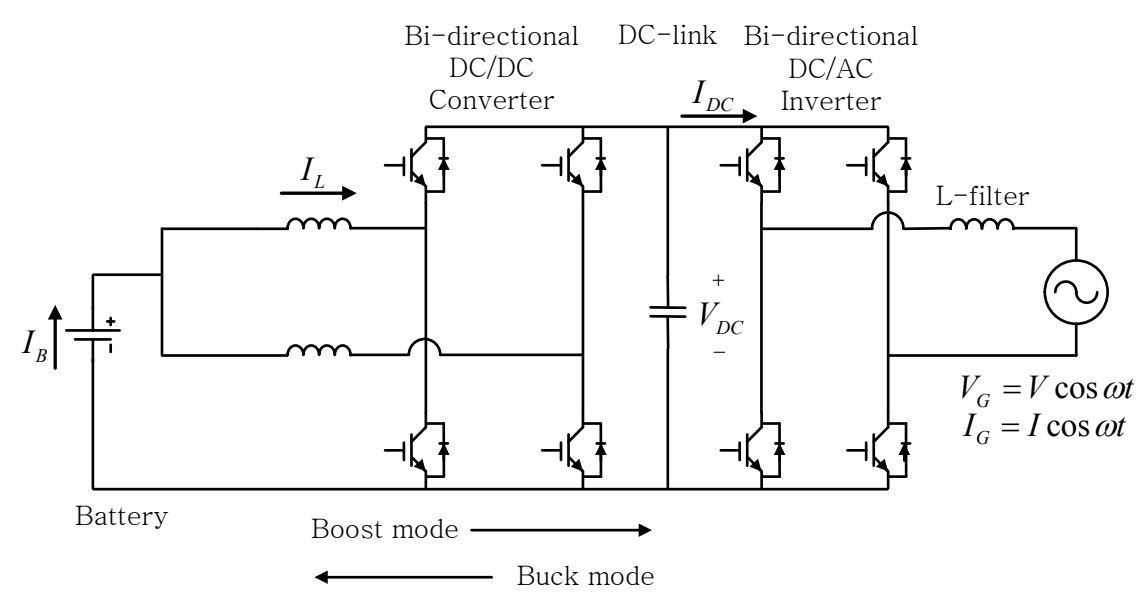

The DC-link-side power is the same as the grid-side power. From Equations (3) and (4), the DC-link-side current can be calculated as:

$$
I_{D C}=\frac{V_{G} I_{G}}{V_{D C}}=\frac{V I}{2 V_{D C}}+\frac{V I}{2 V_{D C}} \cos 2 \omega t=I_{d c}+I_{d c(a c)}
$$


where $I_{d c}$ is DC component and $I_{d c(a c)}$ is AC component.

The DC-link voltage ripple $V_{d c(a c)}$ can be derived by the ripple of the DC-link current $I_{d c(a c)}$. The DC-link voltage ripple $V_{d c(a c)}$ is:

$$
V_{d c(a c)}=\frac{1}{C} \int-I_{d c(a c)} d t=-\frac{V I}{2 V_{D C} \cdot C} \frac{1}{2 \omega} \cdot \sin (2 \omega t)=-\frac{V I}{4 V_{d c} \cdot C \cdot \omega} \cdot \sin (2 \omega t)
$$

From Equation (6), the DC-link voltage has an AC component $V_{d c(a c)}$. Thus $V_{D C}$ and $I_{D C}$ consist of a DC and an AC component. The AC component of $I_{D C}$ and $V_{D C}$ has a second-order harmonic at twice the grid frequency.

Figure 6 shows the equivalent circuit of converter. The battery voltage can be seen as only DC voltage. If there is the power flow between the battery and the DC-link, the battery current $I_{B}$ has an AC component because of $V_{d c(a c)}$. In the same manner, $I_{B}$ has the second-order harmonic at twice the grid frequency.

Figure 6. Equivalent circuit of DC/DC converter.

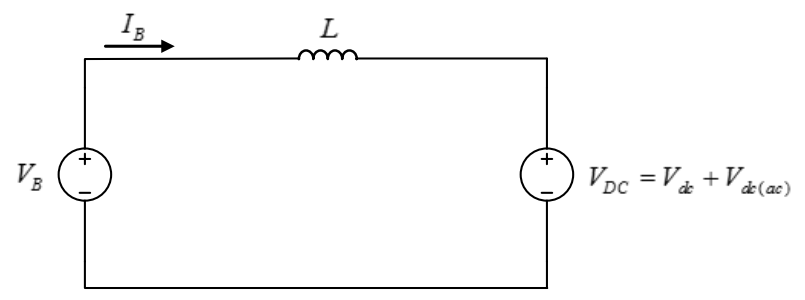

\subsection{Harmonic Reduction Algorithms Using PR Controller}

In a grid connected system, the harmonics adversely affect the efficiency of the power transfer and the power quality. To solve these problems, many harmonic reduction methods which are PPFs, APFs, digital algorithm and others are proposed. However, these harmonic reduction methods have some disadvantages in the stability of a system, limitation of parameters, cost and so on. The PR controller is used in the harmonic compensator to solve the problems mentioned above. In an ideal situation, the PR controller has the characteristics which are the infinity gain, a zero phase shift and narrow bandwidth. The PR controller eliminates the steady-state error when regulating sinusoidal signals. Figure 7 shows the block diagram of the PR controller and the transfer function can be expressed by:

$$
H_{P R}(s)=K_{P R_{-} p}+K_{P R_{-} i} \frac{s}{s^{2}+\omega^{2}}
$$

where $K_{P R_{-} p}$ and $K_{P R_{-} i}$ are gain constants and $\omega$ is the resonant frequency.

Figure 7. Block diagram of the PR controller.

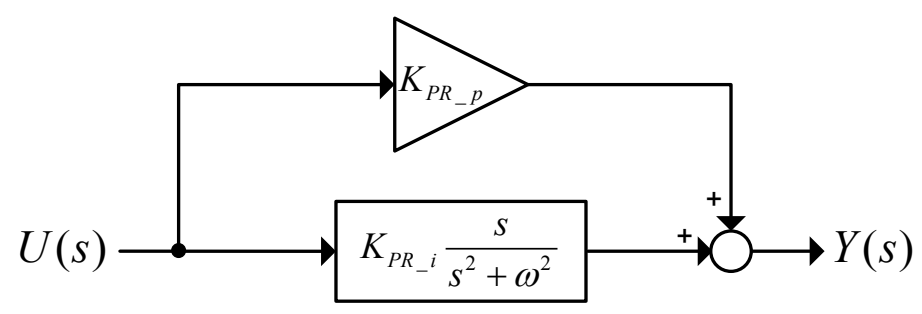


In the ideal condition, the PR controller has an infinite gain at the resonant frequency. However, the nonideal PR controller using a high gain low pass filter (LPF) is used because the infinite gain makes the system unstable. The transfer function of the nonideal PR controller is expressed by:

$$
H_{P R}(s)=K_{P R_{-} p}+K_{P R_{-} i} \frac{\omega_{c} s}{s^{2}+2 \omega_{c} s+\omega^{2}}
$$

where $\omega_{c}$ is the cut-off frequency.

From the equation above, the nonideal PR controller has a sufficiently high finite gain and the bandwidth is adjusted by the cut-off frequency. If the resonant frequency is designed to be the harmonic frequency, the nonideal PR controller can extract and control the harmonic component because of these characteristics mentioned above. The transfer function of the harmonic compensator is expressed by:

$$
H_{H C}(s)=K_{P R_{-} i h} \frac{\omega_{c} s}{s^{2}+2 \omega_{c} s+(h \omega)^{2}}
$$

where $h$ is the harmonic order. To use the second-order harmonic compensator, the resonant frequency is designed to be the frequency of second-order harmonic.

Figure 8 shows the block diagram of the current controller with the second-order harmonic compensator. If the grid frequency is changed, the compensator does not completely extract the second-order harmonic because the PR controller has an arrow bandwidth in the middle of the resonant frequency. Therefore, the compensator using the PR controller does not reduce sufficiently the second-order harmonic under variable conditions.

Figure 8. Block diagram of the current controller with the second-order harmonic compensator using the PR controller.

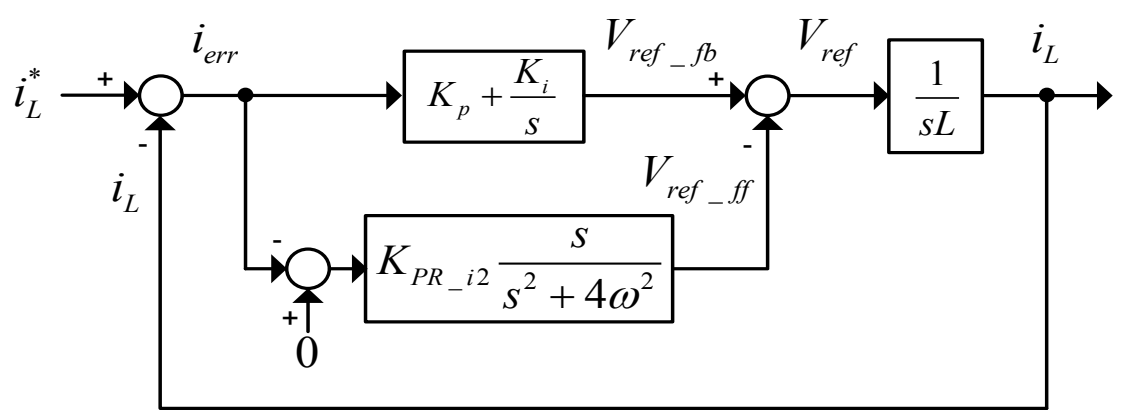

\subsection{Proposed Second-Order Harmonic Reduction Algorithm}

Figure 9 shows a block diagram of the proposed harmonic compensator. To reduce and control the second-order harmonic, the harmonic compensator is required to extract the harmonic components. The current of the battery is composed of AC currents due to the pulsation of the DC-link voltage and DC currents. The current of the battery $I_{B}$ can be expressed by:

$$
I_{B}=\tilde{I}_{B}+\bar{I}_{B}
$$

where " $\sim$ " means the AC component and "-" means the DC component. 
Figure 9. Block diagram of the PI controller with the harmonic compensator.

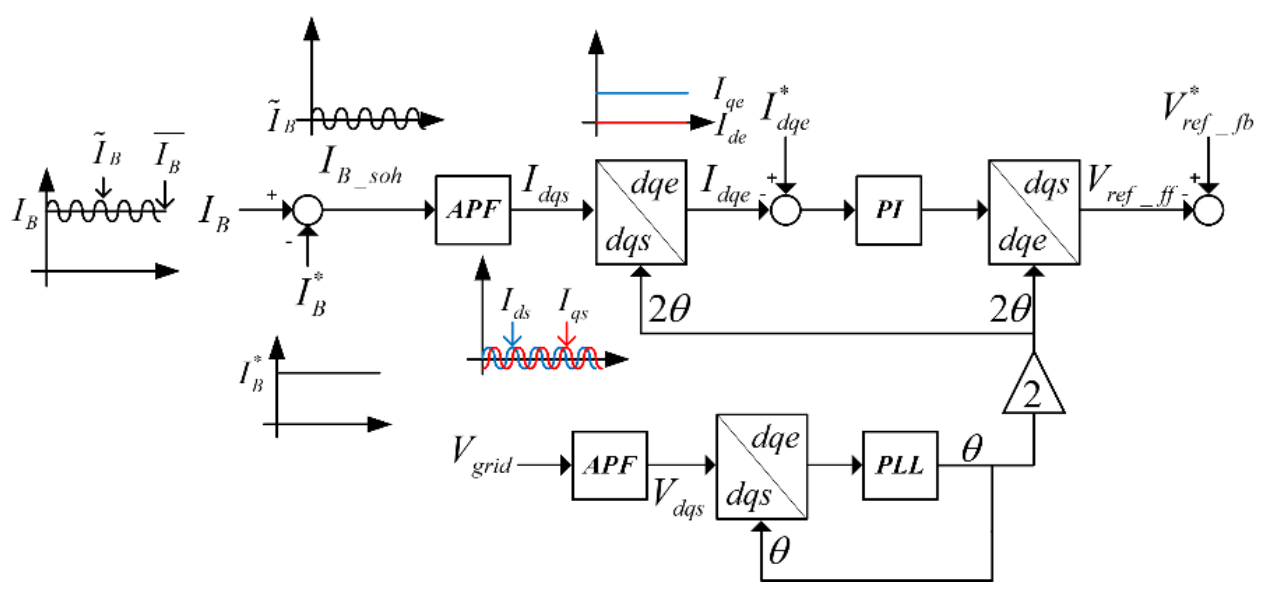

If the battery current tracks the reference current, $\bar{I}_{B}$ is the same as the reference value and $\tilde{I}_{B}$ becomes the ripple component of the current. By subtracting $I_{B}^{*}$ from $I_{B}$, the second-order harmonic $\tilde{I}_{B}$ can be obtained as:

$$
I_{B}-I_{B}^{*}=\tilde{I}_{B}=I_{d s}
$$

The ripple frequency becomes twice the grid frequency. The synchronous reference frame is required to use the PI controller in the proposed harmonic compensator. There is a need for the synchronous reference frame to change the control variable of AC to DC because the PI controller is not suitable to control the signal which has the periodic change such as the AC signal. $I_{d s}$ can be seen as $\tilde{I}_{B}$ converting $I_{d s}$ to the synchronous reference frame. There is a need to create an imaginary axis in single-phase systems. An all pass filter (APF) can be designed to pass all frequencies equally and shift the phase by 90 degrees. The APF is used to make an imaginary axis because of the characteristic mentioned above. An imaginary axis $I_{q s}$ can be made after $I_{d s}$ passes the APF. The frequency of $I_{q s}$ is the same as $I_{d s}$ and the phase of $I_{q s}$ lags behind $I_{d s}$. If $I_{d s}$ and $I_{q s}$ are transferred to the d-q synchronous frame using the exact phase angle of the grid voltage, the second-order harmonic components of the battery current become the DC values as:

$$
\begin{gathered}
I_{d e}=I_{d s} \cos (2 \theta)+I_{q s} \sin (2 \theta) \\
I_{q e}=-I_{d s} \sin (2 \theta)+I_{q s} \cos (2 \theta)
\end{gathered}
$$

where $I_{q e}$ becomes the magnitude of $\tilde{I}_{B}$ and $I_{d e}$ becomes zero.

$I_{d e}$ and $I_{q e}$ are expressed as:

$$
\begin{gathered}
I_{d e}=0 \\
I_{q e}=\tilde{I}_{B_{-} \text {peak }}
\end{gathered}
$$

To control the second-order harmonic component to zero, the reference currents of the dq axis should be zero. Therefore, the inputs of the PI controller are determined as follows:

$$
\begin{gathered}
I_{d e}=0 \\
I_{q e}=\tilde{I}_{B_{-} p e a k}
\end{gathered}
$$


The output of the PI controller is added to the output of the current controller for the compensation of the second-order harmonic. From Equations (12) and (13), the currents of the dq axis which are used in the input of the PI controller are affected by the phase angle of the grid. If a grid voltage fault occurs, due to frequency variation and phase jump and so on, the current of the battery has ripple at twice the changed frequency. As shown in Figure 9, the phase angle, which is used in the synchronous reference frame, is the estimated phase angle, which is obtained by the PLL. Even if the frequency of the grid is changed, the phase angle is estimated by the PLL. In the frequency variation, the harmonic compensator using the PI controller sufficiently reduces the second-order harmonic.

\section{Simulations}

To confirm the validity of the proposed algorithm, the simulation has been performed using the PSIM software. The simulation is operated under the conditions given in Table 1.

Table 1. Simulation conditions.

\begin{tabular}{ccc}
\hline Condition & Value & Unit \\
\hline Rated power & 3 & $\mathrm{KW}$ \\
Grid side voltage & 220 & $\mathrm{Vrms}$ \\
DC-link voltage & 350 & $\mathrm{~V}$ \\
Battery voltage & 250 & $\mathrm{~V}$ \\
Battery-side current & 12 & $\mathrm{~A}$ \\
Grid frequency & 60 & $\mathrm{~Hz}$ \\
Grid-side inductor & 3 & $\mathrm{mH}$ \\
Grid-side resister & 0.02 & $\Omega$ \\
Grid-side switch frequency & 17 & $\mathrm{kHz}$ \\
DC-link capacitor & 4080 & $\mu \mathrm{H}$ \\
Battery-side inductor & 1 & $\mathrm{mH}$ \\
Battery-side switch frequency & 17 & $\mathrm{kHz}$ \\
Switch device & Ideal IGBT & - \\
\hline
\end{tabular}

Figure 10a shows the characteristic operation before the addition of the compensation algorithm in the ESS. When the system operates to the charging mode, the DC/AC inverter controls the DC-link voltage to $350 \mathrm{~V}$ and transfers the power to the DC/DC converter. At this time, the DC-link voltage has ripples at $120 \mathrm{~Hz}$ caused by the pulsating power. The magnitude of the DC-link voltage ripple is approximately $2.3 \mathrm{~A}$, therefore, the current of the battery oscillates around peak-to-peak $8 \mathrm{~A}$ as shown in Figure 10a. Figure10a shows the characteristics of the interleaved topology. The battery current is distributed to the interleaved current. The reference of the interleaved current is half of the reference of the battery current. The average value becomes the reference value because the interleaved current has a triangle shape due to the inductor. The average of the battery current is two times larger than that of the interleaved current as shown in Figure 10a. The interleaved current has the same shape but a different phase by 180 degrees. The current is independently controlled in each phase. Figure $10 \mathrm{~b}$ shows the second-order harmonic component of the battery current at the frequency domain. The battery current has a second-order harmonic component because of the grid power oscillation at twice the grid frequency. The magnitude of second-order harmonic is approximately $4 \mathrm{~A}$, as shown in Figure $10 \mathrm{~b}$. 
Figure 10. Simulation waveform before the harmonic compensation. (a) DC-link voltage and battery current in time domain; (b) Battery current in frequency domain.

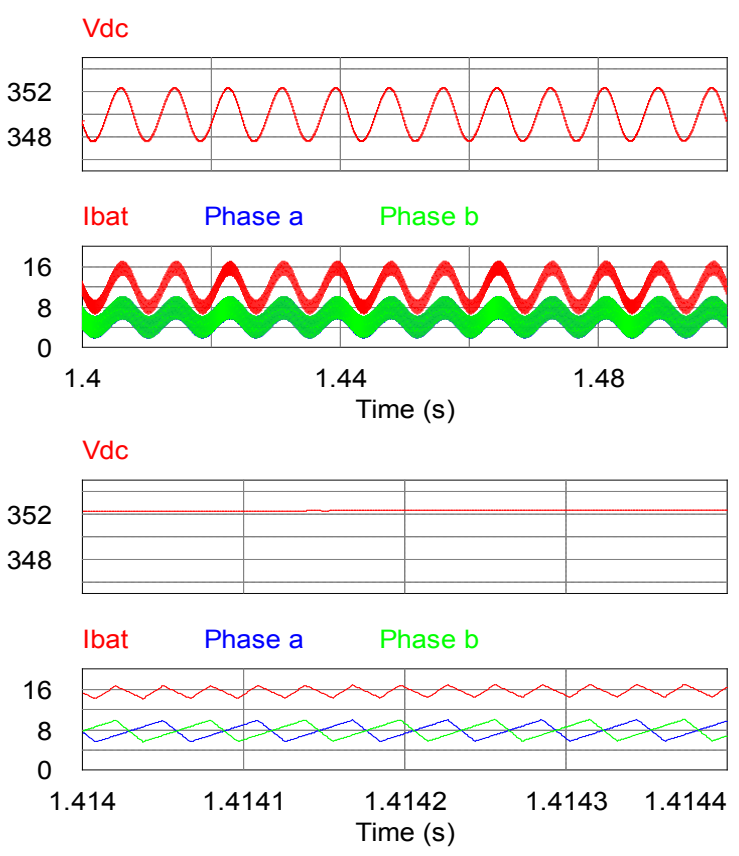

(a)

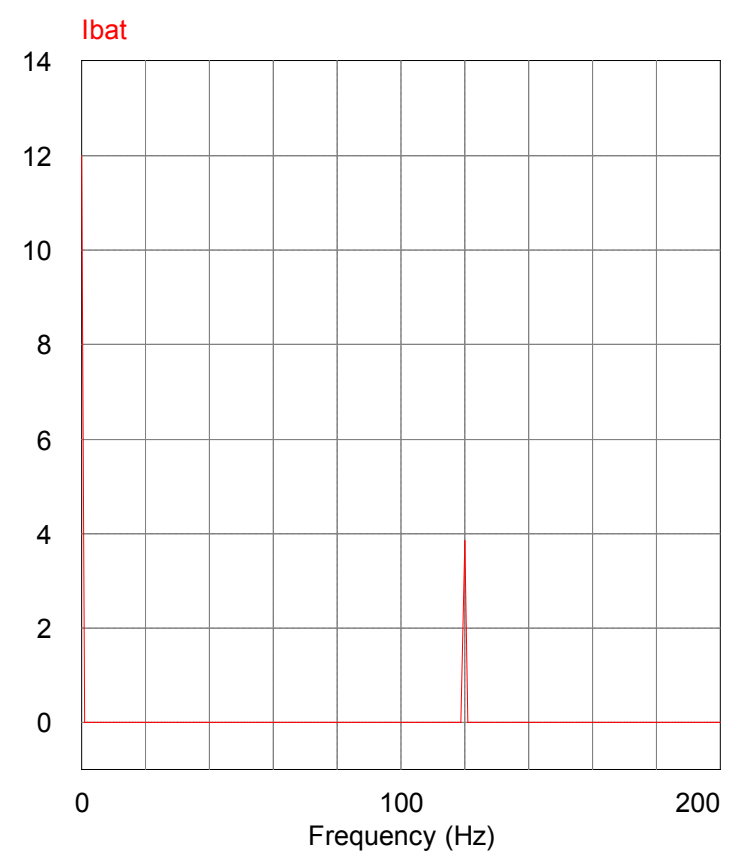

(b)

Figure 11 shows the method which extracts the second-order harmonic of the proposed algorithm under the same conditions as Figure 10. $I_{d s}$ becomes the second-order harmonic from the difference between the battery current and the reference current. The peak value of $I_{d s}$ is approximately 4 A. $I_{q s}$ is created by using the APF. The $I_{q s}$ has the same magnitude and frequency of $I_{d s}$ but the phase is shifted by 90 degrees. In order to use the PI controller, the second-order harmonic component is transferred to the synchronous reference frame. Under this condition, the phase angle of the grid voltage is used in the synchronous reference frame. $I_{q e}$ which has the magnitude of the second-order harmonic is $4 \mathrm{~A}$ and $I_{q e}$ is near zero.

Figure 11. Extraction harmonics of the proposed algorithms.

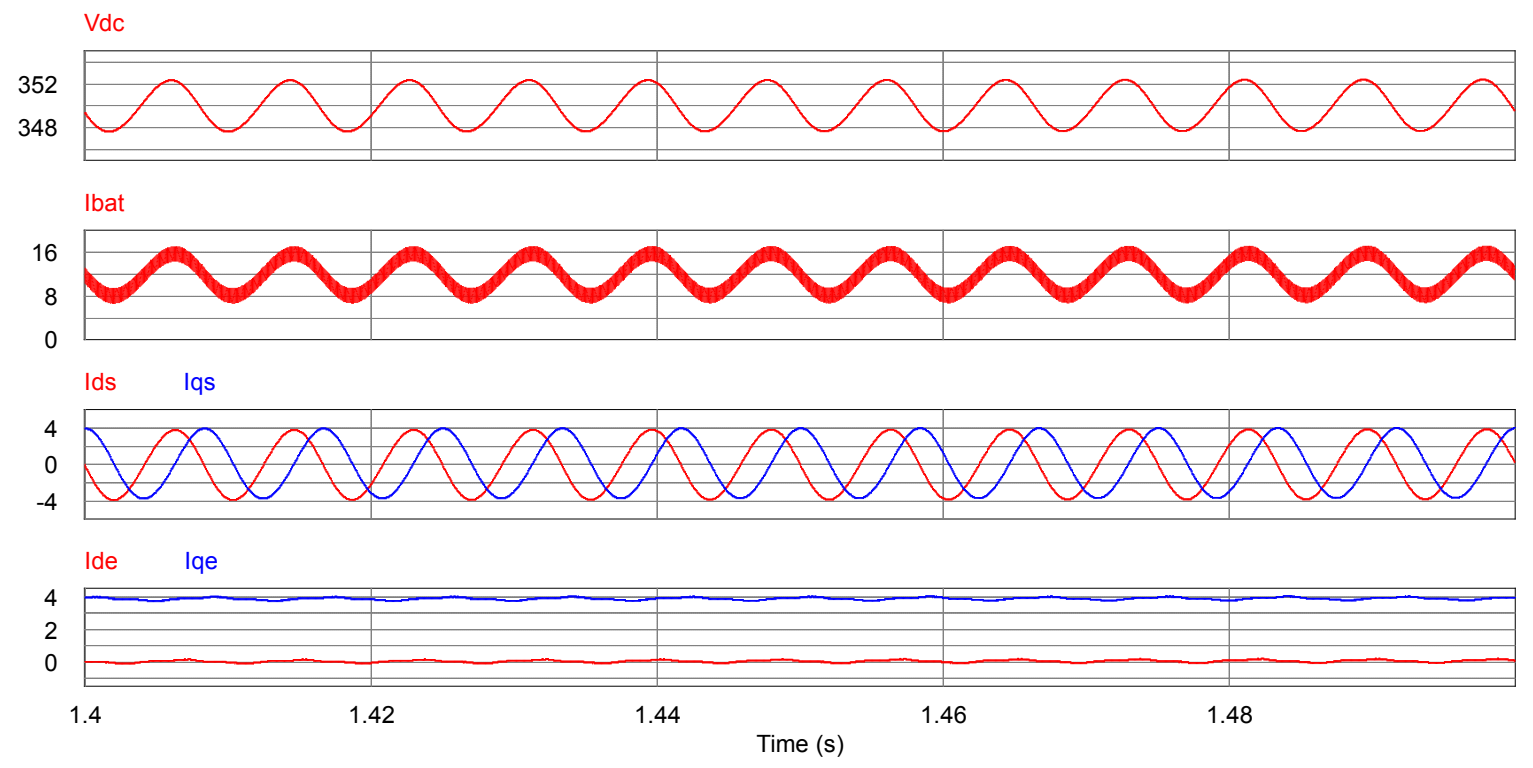


Figure 12a shows the performance of the proposed harmonic reduction algorithm. The DC-link voltage is controlled to an average of $350 \mathrm{~V}$. However, the DC-link voltage has a $120 \mathrm{~Hz}$ ripple. The magnitude of the DC-link voltage ripple is approximately $2.5 \mathrm{~A}$. The battery current is modulated by the DC-link voltage. If the second-order harmonic of the battery current is reduced, the power which is made by the battery current ripple is decrease.

Figure 12. Simulation waveform with the PI compensation. (a) DC-link voltage and battery current in time domain; (b) Battery current in frequency domain.

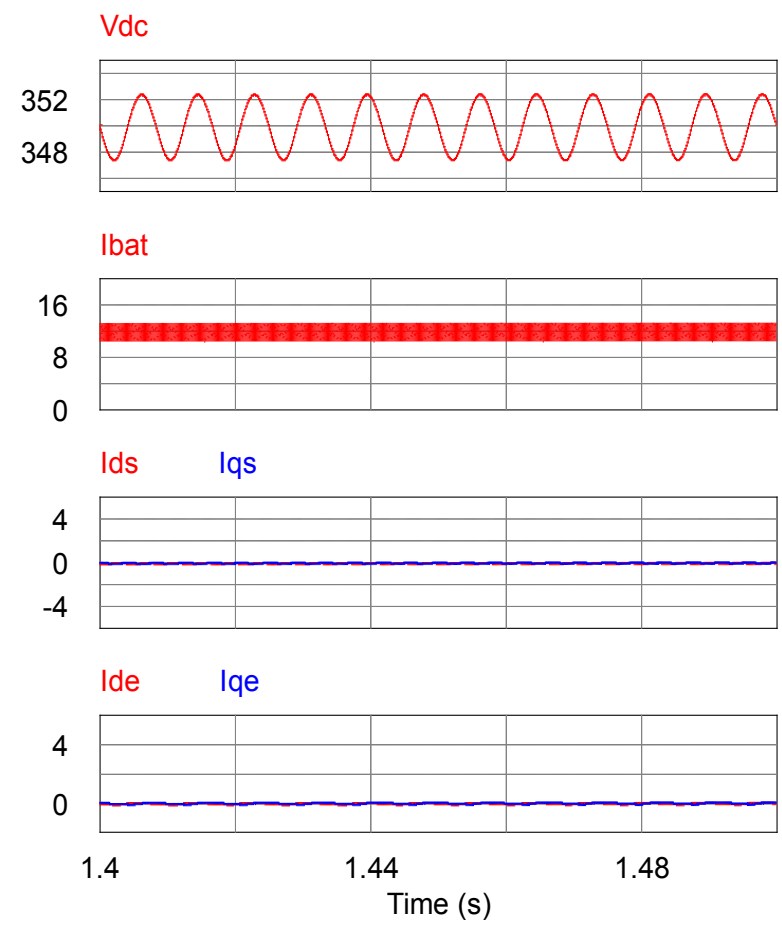

(a)

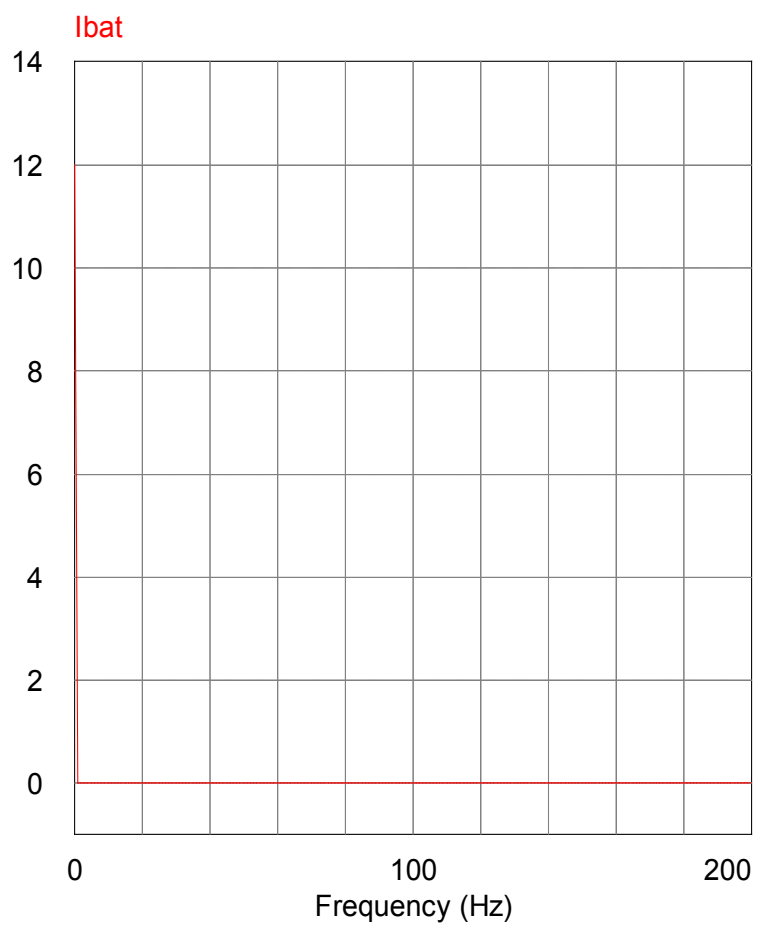

(b)

The ripple of the DC-link is increase because the ripple power is reduced. When Figure 12a is compared with Figure 11a, the DC-link ripple is increase 0.2 A. The DC-link voltage variation is small because the capacitor of the DC-link is relatively large. The second-order harmonic of the battery current is reduced by applying the proposed algorithms. The battery current is controlled to an average of $12 \mathrm{~A}$. However, the switching ripple still remains to the peak-to-peak of 2 A. $I_{d s}$ is reduced to zero because the proposed algorithms compensate the second-order harmonic. Therefore, the magnitude of the second-order harmonic, $I_{q e}$, is controlled to zero. The result of the proposed algorithm shows that the second-order harmonic component is sufficiently reduced as shown in Figure $12 \mathrm{~b}$.

Figure 13 shows the current of the battery with the frequency variation from $60 \mathrm{~Hz}$ to $59 \mathrm{~Hz}$ when the compensation algorithm using the PR controller is added. The PR controller is suitable for the constant frequency operation because the PR controller has the narrow bandwidth in the middle of the resonant frequency. The resonant frequency of the PR controller is designed to be $120 \mathrm{~Hz}$ which is at twice the frequency of the grid. However, the frequency of the second-order harmonic is changed to $118 \mathrm{~Hz}$ under the conditions above. The PR controller cannot sufficiently extract and reduce the changed harmonic component due to the characteristic of the narrow bandwidth. Under this condition, the current ripple 
remains at a peak-to-peak value of 1.2 A as shown in Figure 13a. The result of the compensation using the PR controller shows that the second-order harmonic component remains at $0.6 \mathrm{~A}$ as shown in Figure $13 \mathrm{~b}$.

Figure 13. Simulation waveform with the PR compensation. (a) DC-link voltage and battery current in time domain; (b) Battery current in frequency domain.

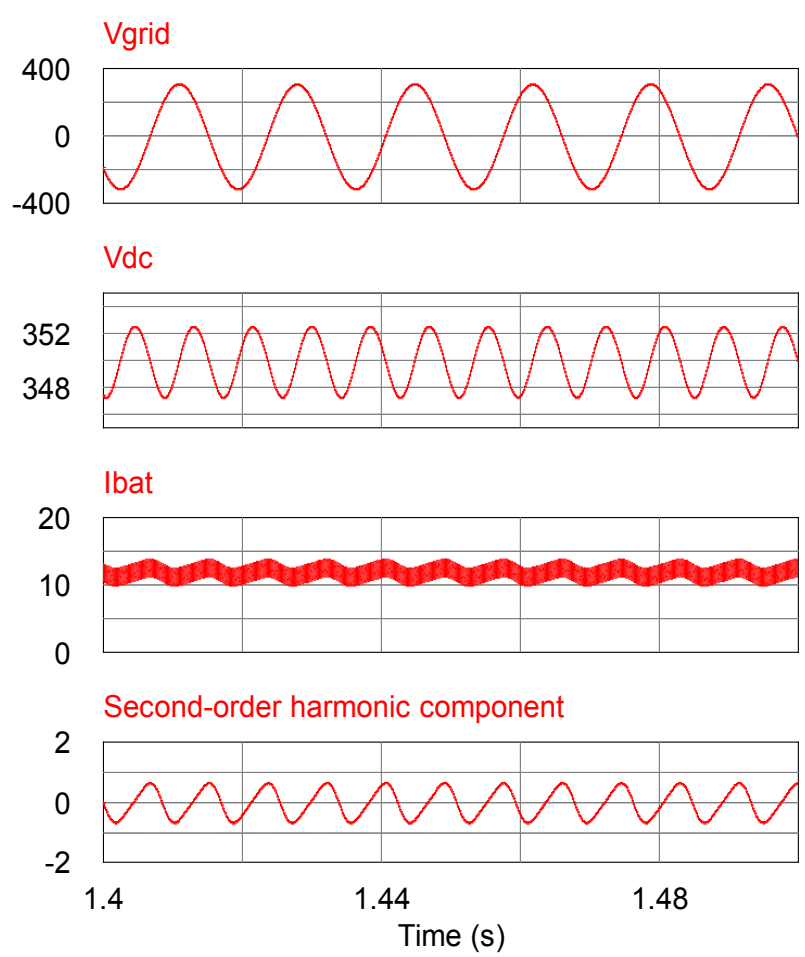

(a)

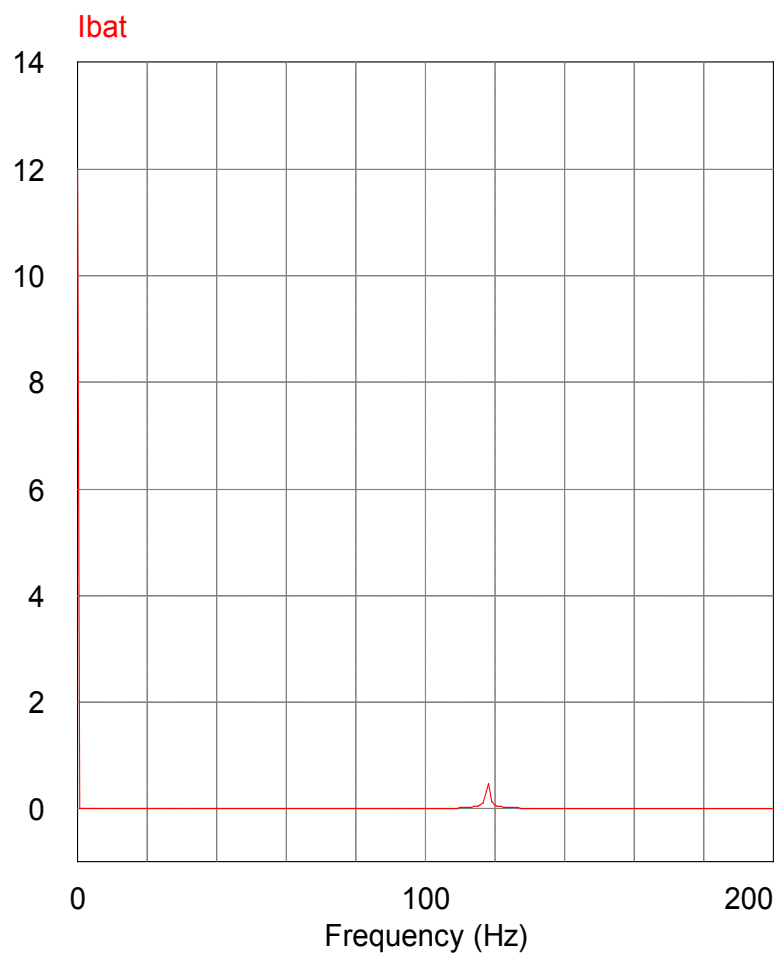

(b)

Figure 14 shows the performance of the proposed compensation technique under the same conditions as Figure 13. The ripple component of the battery current is extracted by the same method shown in Figure 11. The dq axis battery current is affected by the phase angle because the phase angle is used in the synchronous reference frame. Although the frequency is changed, the phase angle is estimated instantaneously by the PLL. Therefore, $I_{d e}$ becomes zero and $I_{q e}$ becomes the magnitude of the ripple component. From the dq axis battery current, the PI controller reduces the ripple component to zero, as shown in Figure 14a. The proposed harmonic compensation algorithm sufficiently reduces the second-order harmonic as shown in Figure 14b. 
Figure 14. Simulation waveform with the PI compensation. (a) DC-link voltage and battery current in time domain; (b) Battery current in frequency domain.

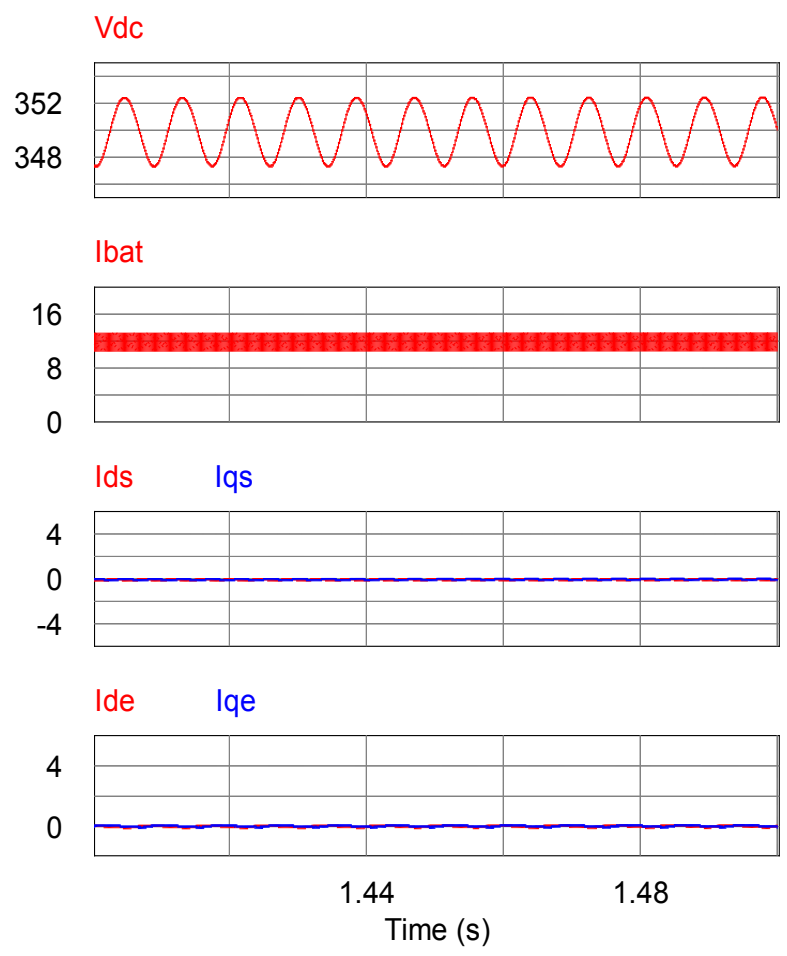

(a)

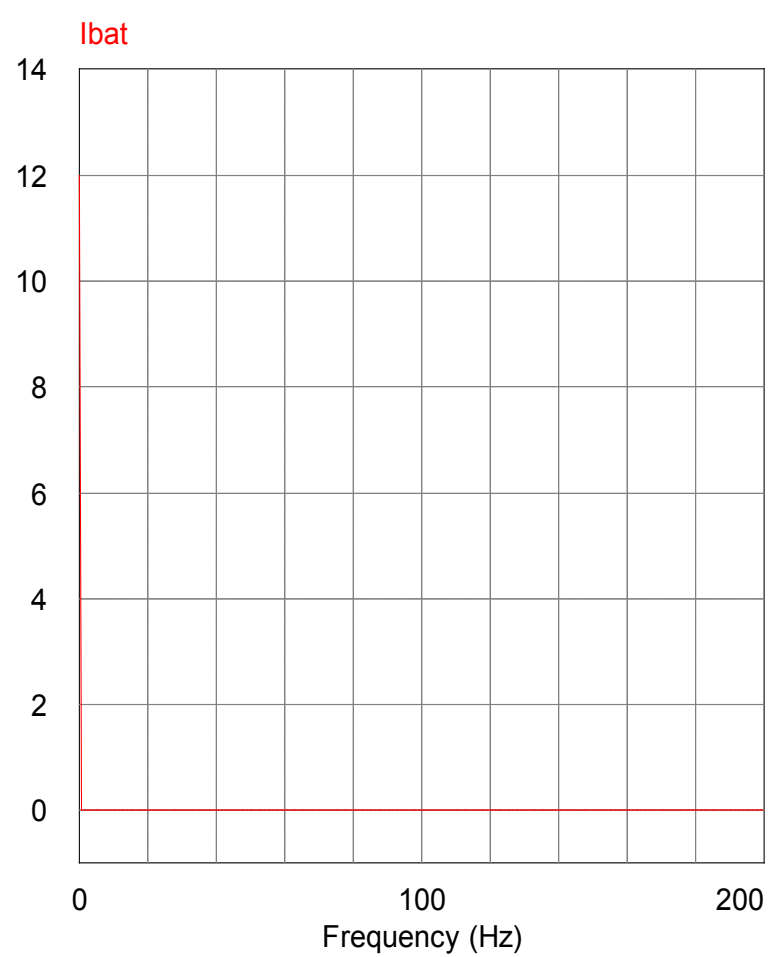

(b)

\section{Experimental Section}

Figure 15 shows the experimental set. The DC/AC inverter is the single-phase system as shown in Figure 15a. The DC/DC converter consists of two inductors due to the interleaved topology.

Figure 15. Experimental set: (a) Inverter and Converter; (b) Control board.

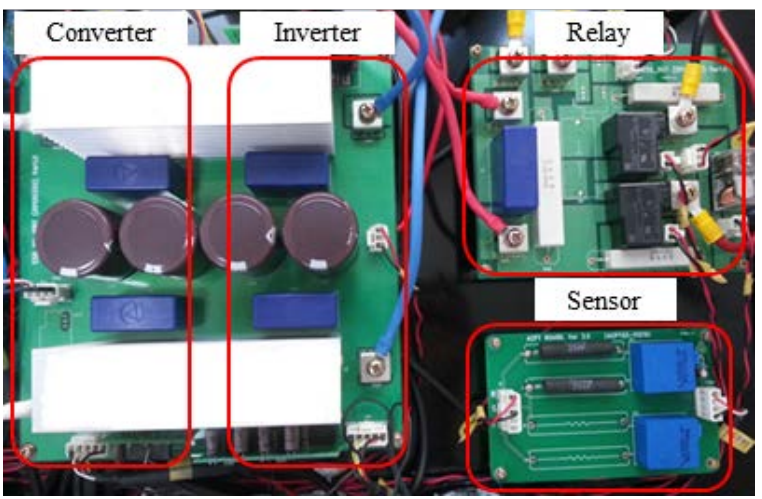

(a)

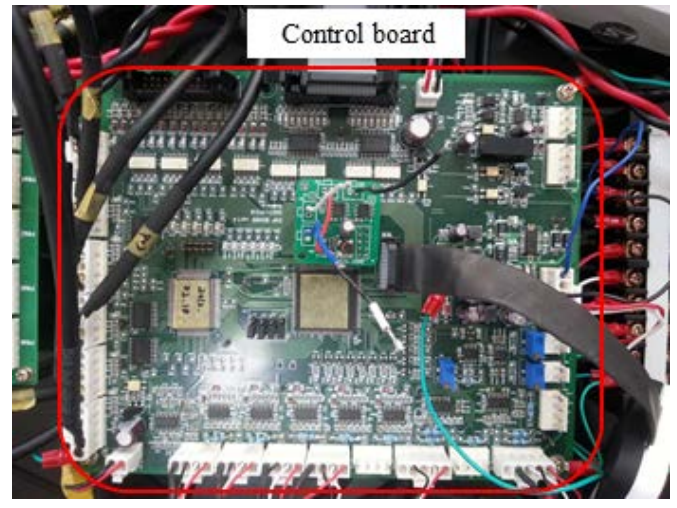

(b)

Each control board is separated, because the inverter and converter are operated independently from each other. The proposed algorithm is programmed on a TMS320F28335 digital signal processor (DSP). The experiment is operated under the conditions given in Table 2. 
Table 2. Experimental conditions.

\begin{tabular}{ccc}
\hline Condition & Value & Unit \\
\hline Rated power & 3 & $\mathrm{~kW}$ \\
Grid side voltage & 220 & $\mathrm{Vrms}$ \\
DC-link voltage & 350 & $\mathrm{~V}$ \\
Battery voltage & 250 & $\mathrm{~V}$ \\
Battery-side current & 12 & $\mathrm{~A}$ \\
Grid frequency & 60 & $\mathrm{~Hz}$ \\
Grid-side inductor & 3 & $\mathrm{mH}$ \\
Grid-side switch frequency & 17 & $\mathrm{kHz}$ \\
DC-link capacitor & 4080 & $\mu \mathrm{H}$ \\
Battery-side inductor & 1 & $\mathrm{mH}$ \\
Battery-side switch frequency & 17 & $\mathrm{kHz}$ \\
Switch device & F4-50R06W1E3 by Infineon & - \\
Battery & Li-ion & - \\
\hline
\end{tabular}

Figure 16 shows the experimental waveform without the second-order harmonic compensation under the rated conditions. Under these conditions, the system is connected to the grid which has a peak value of $311 \mathrm{~V}$, and the ESS operates in the charging mode. The DC/DC converter regulates the output current to $12 \mathrm{~A}$ and the DC/AC inverter controls the DC-link to $350 \mathrm{~V}$ under this condition.

Figure 16. Experimental waveform without the second-order compensation. (a) Time domain; (b) Frequency domain.

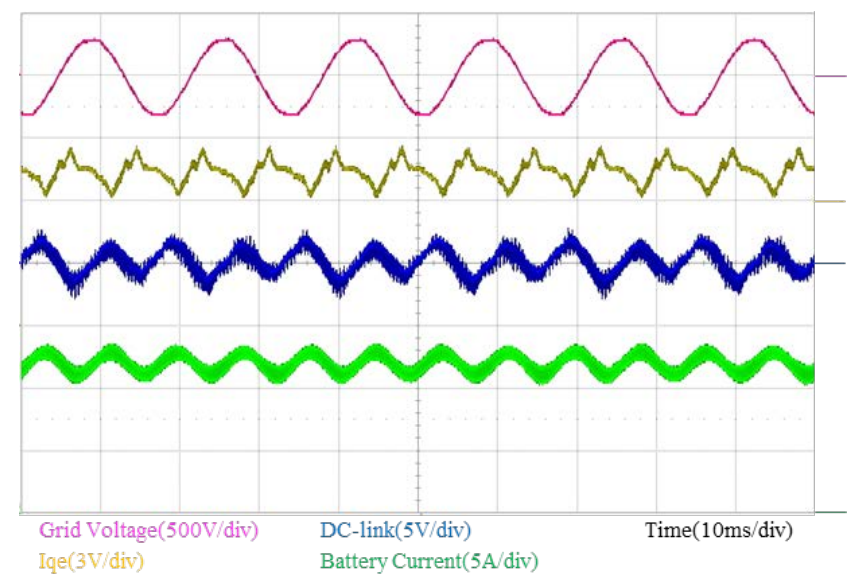

(a)

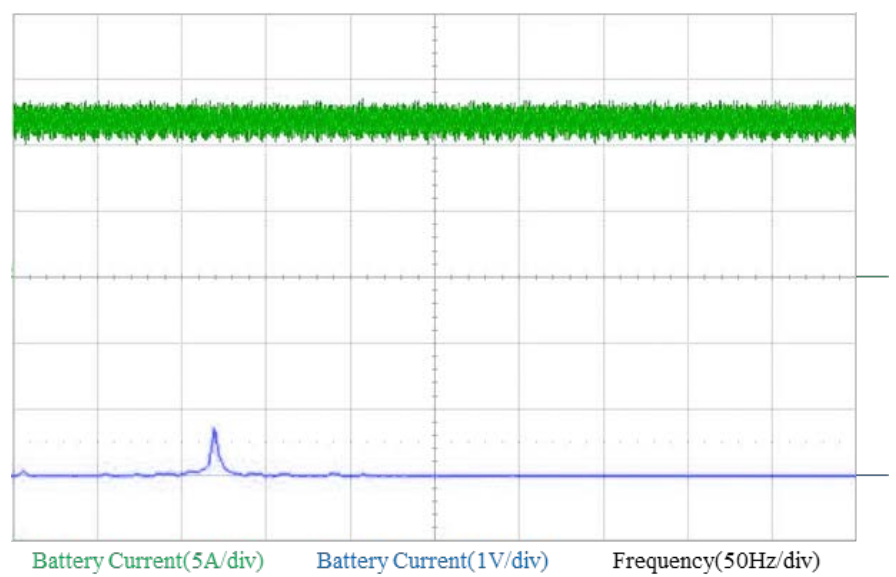

(b)

The DC-link voltage includes a $2 \mathrm{~V}$ ripple component as shown in Figure 16a. In Figure 16a, the current of the battery is pulsating at twice the grid frequency due to the DC-link voltage oscillation. The battery current is $12 \mathrm{~A}$ with a current ripple of $\pm 0.8 \mathrm{~A}(7 \%)$.

In Figure 16a, the ripple component in the synchronous reference frame $\left(i_{q e}\right)$ has the DC offset and $120 \mathrm{~Hz}$ oscillation. The DC offset means the ripple reference and actual value of the battery current. This error does not affect the performance of the proposed compensator because the PI controller of the proposed compensator has a narrow bandwidth. Figure $16 \mathrm{~b}$ shows the battery current in the time and frequency domains. 
The waveform represents the current of the battery pulsating at $120 \mathrm{~Hz}$ in the time domain and the magnitude of the $120 \mathrm{~Hz}$ component is approximately $0.8 \mathrm{~A}$, which is included in the frequency domain.

Figure 17 shows the battery current and interleaved current in the interleaved topology. The sum of the interleaved current is the same as the battery current in the interleaved converter. The interleaved current has the DC offset and ripple component. The DC offset is the average value and the ripple component is generated by the inductors of the converter. When the interleaved current is independently controlled, the average value is the same as the reference current which half the magnitude of the reference battery current.

Figure 17. Battery current and interleaved current in time domain.

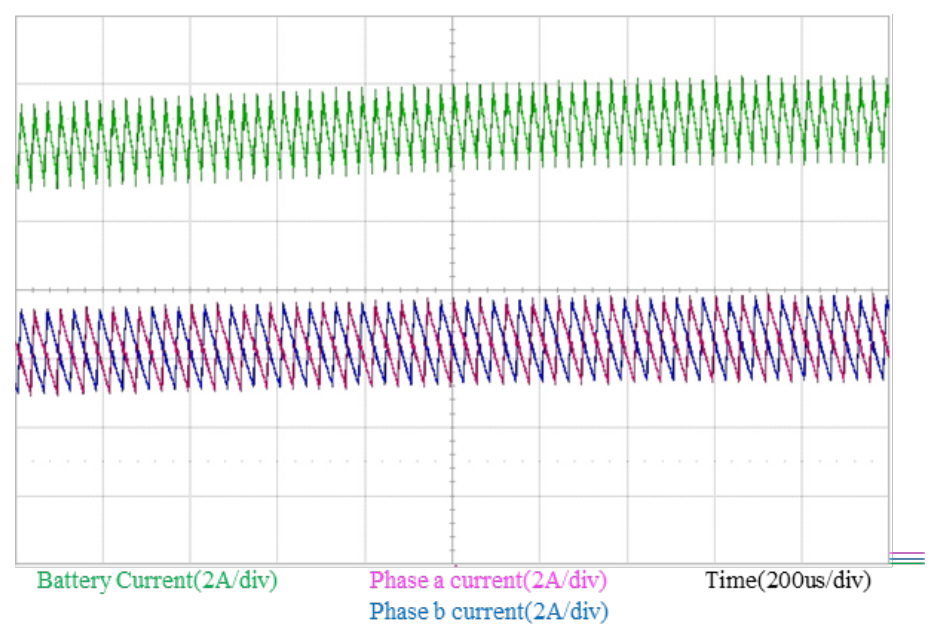

Figure 18 shows the experimental waveform with the second-order harmonic compensation using the PR controller under the variable frequency condition. The grid frequency is changed from $60 \mathrm{~Hz}$ to $59 \mathrm{~Hz}$. When compared to the waveform without the compensation, the ripple of the battery current is small. However, the waveform shows that the current of the battery is still pulsating at twice the grid frequency. After the grid frequency is changed, the PR controller cannot sufficiently extract exactly $118 \mathrm{~Hz}$ because the resonant frequency is designed to be $120 \mathrm{~Hz}$. For this reason, the harmonic compensator using the PR controller clearly cannot reduce the second-order harmonic. The magnitude of the second-order harmonic component remains to be peak-to-peak $0.8 \mathrm{~A}$. Figure $18 \mathrm{~b}$ shows the battery current in the time and frequency domains. The waveform shows that the second-order harmonic component is approximately $0.4 \mathrm{~A}$.

The performance of the proposed second-order harmonic reduction algorithms using the PI controller applied under the same conditions as in Figure 18 is shown in Figure 19. The proposed compensator has not affected the grid voltage and the DC-link voltage as shown in Figure 19a. The DC-link voltage is controlled to $350 \mathrm{~V}$ but is still pulsating at the twice the grid frequency by the oscillation of the grid power. When compared to the waveform without the compensation in Figure 16a, the DC component of $I_{q e}$ becomes smaller because the harmonic compensator has controlled $I_{q e}$ to a value of zero.

The $I_{q e}$ is still pulsating due to other harmonics but the average value of $I_{q e}$ is close to zero. The DC component of $I_{q e}$ is affected by the phase angle. The DC component of $I_{q e}$ becomes the magnitude of the ripple component because the phase angle is instantaneously estimated by the PLL under the 
frequency variable condition. Figure $19 \mathrm{~b}$ shows that the second order harmonic has been almost eliminated by the proposed compensator. The battery current seems to be composed only of the DC component. The ripple component of the battery is completely reduced to zero.

Figure 18. Experimental waveform with PR compensation. (a) Time domain; (b) Frequency domain.

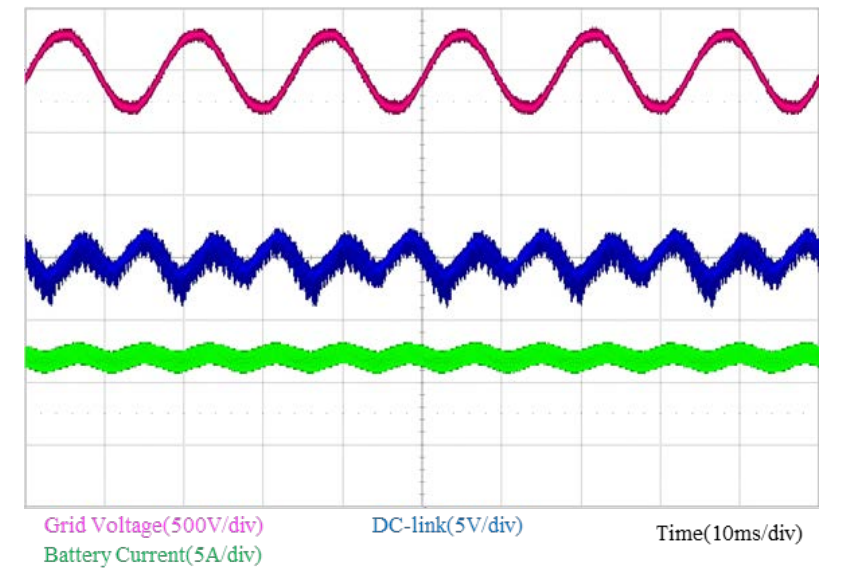

(a)

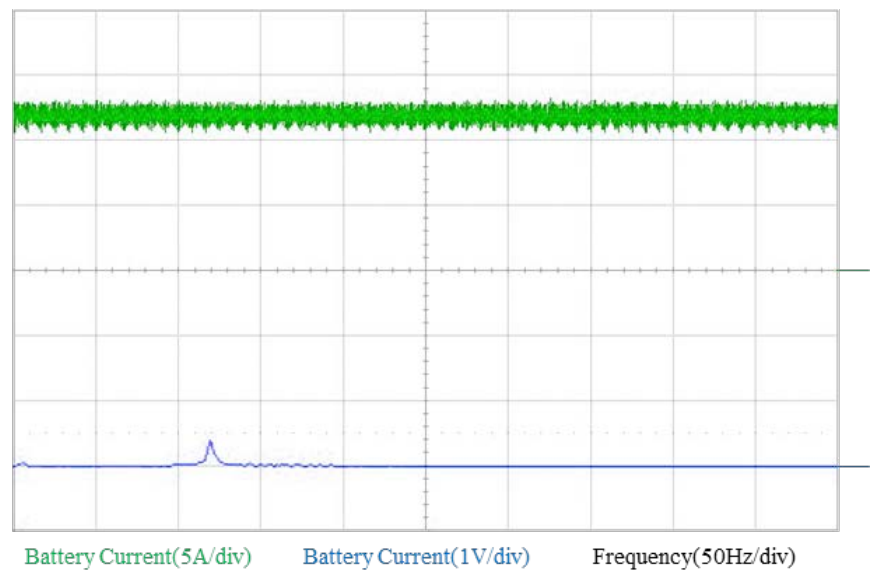

(b)

Figure 19. Experimental waveform with PI compensation: (a) Time domain; (b) Frequency domain.

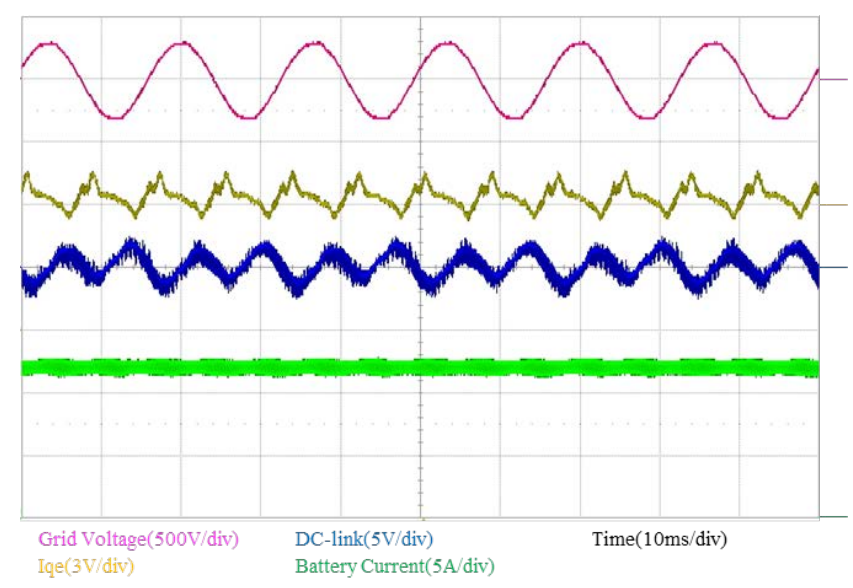

(a)

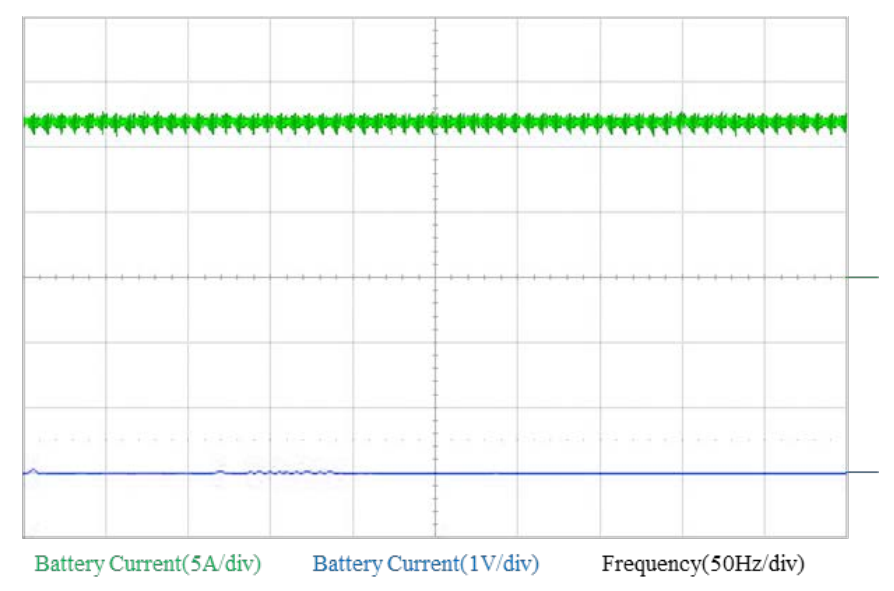

(b)

\section{Conclusions}

This paper has proposed a compensation algorithm of the second-order harmonic in the battery current for an ESS. The proposed algorithm uses the harmonic compensator using the PI controller. The proposed harmonic compensator has the advantage of reducing the output current ripple in the frequency variation, because the synchronous reference frame which is used to control the second-order harmonic has the phase angle estimated by the PLL. The second-order harmonic exists systematically in the output current in single-phase systems. The proposed algorithm can reduce the output current ripple under static and variable frequency conditions. The simulation and experimental 
results have demonstrated that the proposed algorithm can effectively reduce the second-order harmonic of the output current.

\section{Acknowledgments}

This work was supported by the Human Resources Development of the Korea Institute of Energy Technology Evaluation and Planning (KETEP) grant funded by the Korea government Ministry of Knowledge Economy. (No. 20114010203030)

\section{Conflicts of Interest}

The authors declare no conflict of interest.

\section{References}

1. Olaofe, Z.O.; Folly, K.A. Energy Storage Technologies for Small Scale Wind Conversion System. In Proceedings of the IEEE Power Electronics and Machines in Wind Applications (PEMWA), Denver, CO, USA, 16-18 July 2012; pp. 1-5.

2. Liu, X.; Fu, Y.; Peng, J.; Zheng, B. Research and Application on Multi-Mode Energy Storage System Smart Control. In Proceedings of the 14th International Conference on Advanced Communication Technology (ICACT), Pyeong Chang, Korea, 19-22 February 2012; pp. 1289-1293.

3. Wang, Y.; Lin, X.; Pedram, M.; Park, S.Y.; Chang, N.H. Optimal Control of a Grid-Connected Hybrid Electrical Energy Storage System for Homes. In Proceedings of the Design, Automation \& Test in Europe Conference \& Exhibition (DATE), Grenoble, France, 18-22 March 2013; pp. 881-886.

4. Park, S.Y.; Wang, Y.; Kim, Y.H.; Chang, N.H.; Pedram, M. Battery Management for Grid-Connected PV Systems with a Battery. In Proceedings of the 2012 ACM/IEEE International Symposium on Low Power Electronics and Design, New York, NY, USA, 30 July-1 August 2012; pp. 115-120.

5. Liu, C.; Lai, J.S. Low Frequency Current Ripple Reduction Technique with Active Control in a Fuel Cell Power System with Inverter Load. In Proceedings of the IEEE 36th Power Electronics Specialists Conference (PESC), Recife, Brazil, 12-16 June 2007; pp. 2905-2911.

6. Bala, S.; Tengner, T.; Rosenfeld, P.; Delince, F. The Effect of Low Frequency Current Ripple on the Performance of a Lithium Iron Phosphate (LFP) Battery Energy Storage System. In Proceedings of the IEEE Energy Conversion Congress and Exposition (ECCE), Raleigh, NC, USA, 15-20 September 2012; pp. 3485-3492.

7. Ruddell, A.J.; Dutton, A.G.; Wenzl, H.; Ropeter, C.; Sauer, D.U.; Merten, J.; Orfanogiannis, C.; Twidell, J.W.; Vezin, P. Analysis of battery current microcycles in autonomous renewable energy systems. J. Power Sources 2002, 112, 531-546.

8. Uyyuru, K.R.; Mishra, M.K. An optimization-based algorithm for shunt active filter under distorted supply voltages. IEEE Trans. Power Electron. 2009, 24, 1223-1232.

9. Pawar, N.; Paridar, R.D.; Paridar, L.C. An Optimal Controller for APF for Customer Harmonics and Reactive Power Compensation. In Proceedings of the Students Conference on Engineering and Systems (SCES), Allahabad, India, 16-18 March 2012; pp. 1-6. 
10. Safaee, A.; Yazdani, D.; Bakhshai, A.; Jain, P. A Three-Phase Adaptive Harmonic Extraction Approach for Active Power Filters. In Proceedings of the Applied Power Electronics Conference and Exposition (APEC), Fort Worth, TX, USA, 6-11 March 2011; pp. 960-964.

11. Lee, S.H.; An, T.P.; Cha, H.J. Mitigation of low frequency AC Ripple in single-phase photovoltaic power conditioning systems. J. Power Sources 2010, 10, 328-333.

12. Jeong, H.G.; Kim, G.S.; Lee, K.B. Second-order harmonic reduction technique for photovoltaic power conditioning systems using a proportional-resonant controller. Energies 2013, 6, 79-96.

13. Jeong, H.G.; Lee, J.H.; Lee, K.B. A 2nd order harmonic compensation method for wind power system using a PR controller. J. Electr. Eng. Technol. 2013, 8, 507-515.

14. Hwang, J.G.; Lehn, P.W.; Winkelnkemper, M. A generalized class of stationary frame-current controllers for grid-connected AC-DC converters. IEEE Trans Power Deliv. 2010, 25, 2742-2751.

15. Lee, J.H.; Jeong, H.G.; Lee, K.B. Performance improvement of grid-connected inverter systems under unbalanced and distorted grid voltage by using a PR controller. J. Electr. Eng. Technol. 2012, 7, 918-925.

16. Kim, J.K.; Lee, J.H.; Jeong, H.G.; Lee, K.B. Improvement of Grid-connected Inverter Systems PR Controllers under the Unbalanced and Distorted Grid Voltage. In Proceedings of the 7th International Power Electronics and Motion Control Conference (IPEMC), Harbin, China, 2-5 June 2012; pp. 1183-1187.

17. Mohan, N.; Undeland, T.M.; Robbins, W.P. Power Electronics, 3rd ed.; John Wiley \& Sons: New York, NY, USA, 2003; pp. 164-178.

(C) 2013 by the authors; licensee MDPI, Basel, Switzerland. This article is an open access article distributed under the terms and conditions of the Creative Commons Attribution license (http://creativecommons.org/licenses/by/3.0/). 